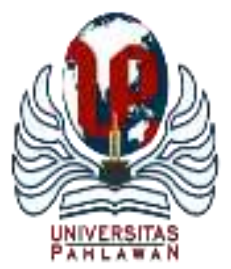

Edukatif : Jurnal Ilmu Pendidikan Volume 3 Nomor 6 Tahun 2021 Halm 5143 - 5149

EDUKATIF: JURNAL ILMU PENDIDIKAN

Research \& Learning in Education

https://edukatif.org/index.php/edukatif/index

\title{
Pendidikan Multikultural: Sebuah Perspektif Global
}

\author{
Allyvia Camelia ${ }^{1 凶}$, Nikmah Suryandari $^{2}$ \\ Universitas Trunojoyo Madura, Indonesia ${ }^{1,2}$ \\ E-mail : allyvia.camelia@trunojoyo.ac.id ${ }^{1}$, nikmahsuryandari@ trunojoyo.ac.id $^{2}$
}

\begin{abstract}
Abstrak
Pendidikan multikultural merupakan pendekatan belajar mengajar yang berlandaskan nilai-nilai demokrasi yang menegaskan pluralisme budaya dalam masyarakat yang beragam. Saat ini ada dua sudut pandang atau perspektif pendidikan multikultural, yaitu perspektif asimilasi atau "melting-pot" dan pluralisme atau sudut pandang umum. Perspektif asimilasi multikultural adalah bahwa mikrokultur harus melepaskan budaya dan identitas asli mereka untuk berbaur atau terserap ke dalam budaya yang dominan. Perspektif global adalah bahwa budaya mikro dapat mempertahankan banyak tradisi mereka seperti bahasa, agama, dan kebiasaan sosial sambil mengadopsi banyak aspek budaya dominan. Perspektif global Pendidikan multikultural mengakui pluralisme budaya sebagai keadaan yang ideal dan sehat dalam setiap masyarakat yang produktif dan mempromosikan kesetaraan dan rasa hormat di antara kelompok budaya yang ada. Prinsip ini memungkinkan perspektif global pendidikan multikultural untuk melampaui pedagogi kesetaraan sebagai satu-satunya cara untuk mengatasi masalah yang telah diciptakan oleh perspektif asimilasi.Dengan interkoneksi yang meningkat pesat di antara semua negara, kita menghadapi isu-isu global terkait ekosistem, senjata nuklir, terorisme, hak asasi manusia, lembaga pendidikan tinggi perlu menerapkan perspektif global pendidikan multikultural di dunia yang pluralistik dan tetap kompetitif secara akademis. Tujuan artikel ini adalah menjelaskan perspektif global tentang pendidikan multikultural dan bagaimana institusi pendidikan tinggi dapat menggunakannya sebagai model keunggulan akademik dalam masyarakat yang pluralistik dan demokratis.
\end{abstract}

Kata Kunci: pendidikan multicultural, perguruan tinggi, melting pot.

\begin{abstract}
Multicultural education is a teaching and learning approach based on democratic values that affirm cultural pluralism in diverse societies. There are currently two points of view or perspectives of multicultural education, namely the perspective of assimilation or "melting-pot" and pluralism or "general point of view. The perspective of multicultural assimilation is that microcultures must shed their indigenous cultures and identities in order to blend in or be absorbed into the dominant culture. The global perspective is that micro cultures can maintain many of their traditions such as language, religion, and social customs while adopting many aspects of dominant culture. Multicultural education recognizes cultural pluralism as an ideal and healthy state in any productive society and promotes equality and respect among existing cultural groups. This principle allows the global perspective of multicultural education to go beyond equality pedagogy as the only way to address the problems that have been created by the assimilation perspective. With rapidly increasing interconnections among all countries, we face global issues related to ecosystems, nuclear weapons, terrorism, human rights, higher education institutions need to apply a global perspective of multicultural education in a pluralistic world and remain academically competitive. The purpose of this article is to explain the global perspective on multicultural education and how higher education institutions can use it as a model of academic excellence in a pluralistic and democratic society.
\end{abstract}

Keywords: content, formatting, article.

Copyright (c) 2021 Allyvia Camelia, Nikmah Suryandari

$\triangle$ Corresponding author

Email : allyvia.camelia@trunojoyo.ac.id

DOI : https://doi.org/10.31004/edukatif.v3i6.1649

ISSN 2656-8063 (Media Cetak)

ISSN 2656-8071 (Media Online)

Edukatif : Jurnal Ilmu Pendidikan Vol 3 No 6 Tahun 2021 p-ISSN 2656-8063 e-ISSN 2656-8071 


\section{PENDAHULUAN}

Wacana multikulturalisme dalam konteks pendidikan saat ini, menjadi isu penting dalam upaya pembangunan masyarakat di Indonesia (Primawati, 2013). Hal ini dilakukan dengan beberapa alasan, diantaranya pertama bahwa Tuhan secara alami menciptakan manusia dalam keragaman. Alasan kedua adalah kejadian konflik sosial ditengarai karena kurangnya penghargaan akan perbedaan. Menurut James Banks (Lestari, 2015) pendidikan multikultural adalah konsep atau ide sebagai suatu rangkaian kepercayaan (set of beliefe) dan penjelasan yang mengakui dan menilai pentingnya keragaman budaya dan etnis dalam membentuk gaya hidup, pengalaman sosial, identitas pribadi, dan kesempatan-kesempatan pendidikan dari individu, kelompok maupun negara. Pendidikan multikultural didefinisikan juga sebagai pendidikan untuk people of color, kemudian bagaimana kita mampu menyikapinya dengan penuh toleran dan semangat egaliter.

Masyarakat Indonesia yang dikenal dengan plural akan mudah mengalami gejolak dis-itegrasi bila tidak ada kesepahaman nilai-nilai multikultur, salah satu contohnya adalah banyaknya kerusuhan dan bentrokan antar warga di tengah gejolak masyarakat, jika tidak ada solusi pencegahan akan berdampak pada bahayanya nilai-nilai kesatuan dan keutuhan bangsa serta tegaknya NKRI. Kenyataan ini dapat dilihat dari kondisi sosiokultural maupun geografis yang begitu beragam dan luas (Ali, 2000).

Menurut Ambar Sri Lestari (Lestari, 2015) di Indonesia sendiri, paradigma multikultural secara implisit menjadi concern dari Pasal 4 UU N0. 20 Tahun 2003 tentang Sistem Pendidikan Nasional. Dalam pasal itu dijelaskan, bahwa pendidikan diselenggarakan secara demokratis, tidak diskriminatif dengan menjunjung tinggi HAM, nilai keagamaan, nilai kultural dan kemajemukan bangsa. Oleh sebab itu maka pendidikan multikultural harus senantiasa di sosialisasikan dan didesiminasikan melalui pendidikan yang dituangkan didalam kurikulum sekolah, sehingga anak sejak dini diajarkan sikap toleransi, menghargai, mengasihi dan menerima perbedaan menjadi sebuah konsep yang terinternalisasikan dalam diri seseorang.

Shulman \& Mesa-Bains(Shulman \& Mesa-Bains, 2020) mengidentifikasi beberapa manfaat jangka panjang dari perspektif global pendidikan multikultural. Beberapa di antara manfaat jangka Panjang Pendidikan multicultural adalah : meningkatkan produktivitas karena tersedianya berbagai sumber daya mental untuk menyelesaikan pendidikan tugas yang sama dan mendorong pertumbuhan kognitif dan moral di antara semua orang. Pendidikan multikultural meningkatkan keterampilan pemecahan masalah secara kreatif melalui perspektif berbeda yang diterapkan pada masalah yang sama untuk mencapai solusi. Pendidikan multikultural meningkatkan hubungan positif melalui pencapaian tujuan bersama, rasa hormat, penghargaan, dan komitmen terhadap kesetaraan di antara para intelektual di lembaga pendidikan tinggi. Pendidikan multikultural mengurangi stereotip dan prasangka melalui kontak langsung dan interaksi antar individu yang beragam. Pendidikan multikultural memperbaharui ketahanan masyarakat melalui kekayaan budaya yang berbeda dari anggotanya dan mendorong perkembangan pandangan dunia yang lebih luas dan canggih.

Sampai saat ini, pandangan utama pendidikan multikultural di dunia adalah asimilasi atau perspektif "melting-pot" (McNergney et al., 2001) di mana budaya mikro diharapkan melepaskan identitas budaya mereka untuk berbaur atau terserap. oleh masyarakat arus utama atau budaya makro (Bennett, 1986). Dalam perspektif asimilasi atau "melting-pot". Pada pengembangan budaya bersama (shared cultures), anggota budaya mikro diterima hanya setelah mereka melepaskan identitas asli, nilai-nilai, gaya perilaku, bahasa, dan gaya komunikasi nonverbal mereka. Dalam perspektif asimilasi, kekhasan budaya lainnya dan identifikasi dengan cara hidup yang berbeda dianggap tidak dapat diterima,rendah, dan merupakan ancaman bagi persatuan bangsa. Segala sesuatu yang mungkin adalah dilakukan oleh budaya populer untuk menekan budaya lain dan kontribusi kelompok lain (Bennett, 1986). Menurut data Sensus di Amerika Serikat, 2002, meskipun tujuan awal perspektif asimilasi atau "melting-pot" adalah untuk menciptakan kesatuan melalui pengembangan budaya bersama karena setiap mikrokultur diserap ke dalam makrokultur bersama, dalam kenyataannya menjadi lebih sulit untuk mencapai demokrasi luas di antara mikrokultur karena budaya yang dihasilkan tidak mencerminkan budaya dan keragaman dalam bangsa. 


\section{Pendidikan Multikultural: Sebuah Perspektif Global - Allyvia Camelia, Nikmah Suryandari DOI: https://doi.org/10.31004/edukatif.v3i6.1649}

Dengan interkoneksi yang meningkat pesat di antara semua negara di dunia, khususnya, saat kita menghadapi masalah global yang berkaitan dengan ekosistem, senjata nuklir, terorisme, hak asasi manusia, dan sumber daya nasional yang langka, ruang lingkup pendidikan multikultural perlu diperluas untuk memasukkan nilai-nilai demokrasi, pluralisme budaya dalam budaya di masyarakat lintas, nasional, dan saling ketergantungan global. Perspektif global multikultural pendidikan memungkinkan promosi nilai-nilai ini serta promosi kesetaraan di antara semua budaya kelompok dalam masyarakat, yang terakhir terutama telah diperburuk selama asimilasi atau era "melting-pot" pendidikan multikultural. Perspektif global pendidikan multikultural memungkinkan individu untuk mengembangkan rasa hormat dan penghargaan untuk semua kelompok budaya yang ada.

Kerangka konseptual perspektif global pendidikan multikultural diturunkan dari empat dimensi interaktif utama, yaitu, kompetensi multikultural, pedagogi kesetaraan, reformasi kurikulum, dan pengajaran untuk keadilan sosial.

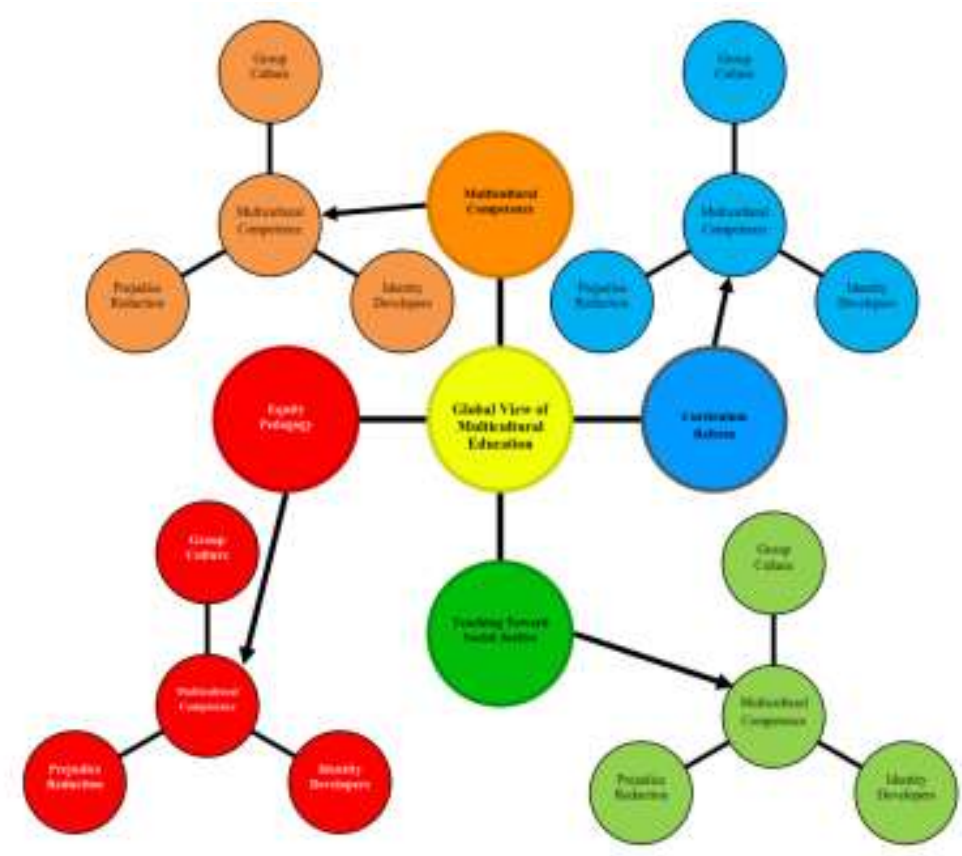

Gambar 1: Kerangka Konsep Pendidikan Multikultural

Gambar diatas menunjukkan empat komponen utama dalam kerangka konseptual perspektif global pendidikan multikultural. Pertama, Kompetensi multikultural adalah proses di mana seseorang mengembangkan kompetensi dalam berbagai cara untuk memahami, mengevaluasi, mempercayai, dan memecahkan masalah. Tujuannya adalah untuk fokus pada pemahaman dan pembelajaran untuk menegosiasikan keragaman budaya antar bangsa serta dalam satu negara dengan menjadi sadar akan perspektifnya sendiri serta menjadi sadar akan perspektif budaya lain sebagai dasar interaksi lintas budaya. Kedua, kurikulum perlu direformasi dengan memasukkan teori kurikulum dan sejarah sehingga kemungkinan bias dalam buku teks, media, dan materi pendidikan lainnya dapat dideteksi dengan mudah oleh pendidik, siswa, dan pemangku kepentingan lainnya. Reformasi kurikulum berusaha untuk memperluas isi kursus tradisional yang terutama monoetnis dan Anglo-Eropa (diAmerika Serikat) melalui masuknya perspektif multietnis dan global. Bagi sebagian besar pendidik, reformasi ini membutuhkan keterlibatan aktif dan pengembangan pengetahuan dan pemahaman baru tentang kontribusi historis kelompok etnis. Pedagogi kesetaraan menjadi komponen penting dari reformasi multikultural. Pedagogi kesetaraan bertujuan untuk mencapai kesempatan pendidikan yang adil dan setara untuk semua anak bangsa, termasuk yang kurang beruntung secara sosial ekonomi dan etnis minoritas di masyarakat multikultur. Pedagogi kesetaraan juga 


\section{Pendidikan Multikultural: Sebuah Perspektif Global - Allyvia Camelia, Nikmah Suryandari DOI: https://doi.org/10.31004/edukatif.v3i6.1649}

mengharuskan pendidik mengembangkan pemahaman tentang perbedaan tentang gaya belajar siswa untuk lebih berkembang dan berfokus pada budaya mereka dan penghormatan terhadap budaya. Untuk dapat melakukan ini,pendidik perlu mengembangkan pengetahuan pedagogis, keterampilan, dan disposisi yang memungkinkan mereka untuk mengadaptasi metode pengajaran alternatif atau memodifikasi strategi instruksional dalam budaya ruang kelas yang beragam. Pedagogi kesetaraan adalah untuk memastikan pencapaian standar tertinggi dalam keunggulan akademik di antara semua siswa. Iklim sekolah dan ruang kelas juga harus diubah agar keberhasilan akademik dapat dicapai oleh siswa dari semua kelompok budaya. Terakhir, pengajaran menuju keadilan sosial membutuhkan pemahaman yang memadai tentang demografi siswa, budaya, dan ras dalam budaya populer, dan perkembangan sosial keterampilan tindakan. Ini juga menekankan pembersihan mitos dan stereotip yang terkait dengan gender,usia, dan berbagai ras dan kelompok etnis dengan menekankan kesamaan dasar manusia (Nieto \& Bode, 2018). Selain itu, pengajaran menuju keadilan sosial mempromosikan pengembangan kesadaran akan akar sejarah dan pemahaman tentang bukti prasangka individu dan institusional, diskriminasi seperti rasisme budaya, seksisme, klasisme, dan bentuk prasangka lainnya.

Tujuan utama dari pendidikan multikultural adalah mengembangkan tanggung jawab kepada masyarakat dunia, bentuk penghormatan pada bumi, penerimaan dan penghargaan terhadap keragaman budaya, serta menghormati martabat manusia. Tujuan kedua adalah mengembangkan beragam perspektif sejarah, tujuan selanjutnya adalah untuk memperkuat kesadaran budaya dan memperkuat kompetensi antarbudaya.Tujuan ketiga untuk memerangi rasisme, seksisme, bentuk prasangka lainnya, diskriminasi. Terakhir adalah untuk untuk meningkatkan kesadaran kondisi dan dinamika global.

\section{METODE PENELITIAN}

Kajian ini menggunakan metode penelitian studi literatur, yaitu penelitian terhadap buku, jurnal, karya tulis dll. Jenis metode penelitian ini berfungsi dalam mencari informai sesuai referensi atau informan tertentu yang sesuai dengan masalah yang dibahas. Studi kepustakaan adalah teknik pengumpulan data dengan mengadakan studi penelaahan terhadap buku-buku, literatur-literatur, catatan-catatan, dan laporan-laporan yang ada hubungannya dengan masalah yang dipecahkan(Nazir, 1985). Sedangkan menurut Ruslan (Ruslan, 2006) studi kepustakaan adalah dilakukan mencari data atau informasi riset melalui membaca jurnal ilmiah, buku-buku referensi dan bahan bahan publikasi yang tersedia di perpustakaan. Studi kepustakaan memuat uraian sistematis tentang kajian literatur dan hasil penelitian sebelumnya yang ada hubungannya dengan penelitian yang akan dilakukan dan diusahakan menunjukkan kondisi mutakhir dari bidang ilmu tersebut. Pustaka yang dikaji dalam tulisan ini adalah beragam tulisan jurnal maupun buku yang relevan dengan tema, yaitu tentang pendidikan multicultural.

\section{HASIL DAN PEMBAHASAN PENELITIAN}

\section{Mengapa Institusi Pendidikan Tinggi?}

Institusi pendidikan tinggi di sebagian besar wilayah dunia memiliki populasi mahasiswa yang beragam secara budaya. Pluralisme budaya ini membuat model demokrasi dan interaksi yang pluralistik . Dengan demikian, penerapan prinsip inti perspektif global mengenai pendidikan multikultural dalam praktik belajarmengajar menjadi sangat penting.

Pendidikan memiliki peranan penting dalam memberikan pemahaman kepada masyarakat bahwa negara Indonesia adalah negara yang dikenal sebagai negara dengan latarbelakang sosial, agama, etnik, budaya, yang beragam. Menurut Budimansyah(Budimansyah, 2012) unsur-unsur yang membentuk bangsa dan negara Indonesia adalah suku bangsa, kepulauan, kebudayaan, golongan, dan agama. Persatuan bangsa dan wilayah negara Indonesia digambarkan dalam lambing negara Garuda Pancasila dengan semboyan Bhinneka Tunggal 


\section{Pendidikan Multikultural: Sebuah Perspektif Global - Allyvia Camelia, Nikmah Suryandari DOI: https://doi.org/10.31004/edukatif.v3i6.1649}

Ika. Membangun keharmonisan melalui multikultural, berkaitan dengan tugas pendidikan adalah untuk mencerdaskan kehidupan bangsa. Paradigma multikultural secara implisit menjadi perhatian dari Pasal 4 UU N0. 20 Tahun 2003 tentang Sistem Pendidikan Nasional. Dalam pasal itu dijelaskan, bahwa pendidikan diselenggarakan secara demokratis, tidak diskriminatif dengan menjunjung tinggi HAM, nilai keagamaan, nilai kultural dan kemajemukan bangsa. Oleh sebab itu maka pendidikan multikultural harus senantiasa di sosialisasikan dan didesiminasikan melalui pendidikan yang dituangkan didalam kurikulum sekolah, sehingga anak sejak dini diajarkan sikap toleransi, menghargai, mengasihi dan menerima perbedaan menjadi sebuah konsep yang terinternalisasikan dalam diri seseorang (Lestari, 2015).

Pembelajaran multikultural adalah kebijakan dalam praktik pendidikan dalam mengakui, menerima dan menegaskan perbedaan dan persamaan manusia yang dikaitkan dengan gender, ras, kelas (Christine E. Sleeter, 2007). Pembelajaran multicultural pada dasarnya merupakan program pendidikan bangsa agar komunitas multikultural dapat berpartisipasi dalam mewujudkan kehidupan demokrasi yang ideal bagi bangsanya(Banks, 1993).

Menurut Waston dan Abdullah Aly (Waston, 2018) pendidikan yang ramah terhadap keragaman menjadi semakin dibutuhkan dalam kondisi tersebut. Salah satu konsep yang paling banyak diterima oleh masyarakat internasional adalah pendidikan multikultural. Model pendidikan tersebut menjamin terwujudnya pencapaian optimal dalam pendidikan sehingga setiap entitas dapat meraih prestasi sesuai upayanya. Pendidikan multikultural bahkan menjanjikan kesetaraan dalam prosesnya sehingga setiap budaya dan agama tidak ada yang mengalami diskriminasi, bahkan minoritas tidak akan terdesak oleh mayoritas.

Hubungan di antara populasi yang beragam di pendidikan tinggi ini sekarang lebih penting daripada sebelumnya. Institusi pendidikan tinggi telah menjadi model masyarakat di mana mereka berada, dan dengan demikian telah menjadi pilar keunggulan akademik, model untuk kompetensi multicultural dalam masyarakat, dan model untuk dunia yang saling bergantung, serta model untuk kesetaraan dan nilai-nilai demokrasi. Institusi Pendidikan Tinggi adalah model keunggulan akademik. Prinsip dan prinsip pendidikan multikultural memungkinkan untuk mempromosikan keunggulan dalam kinerja semua peserta didik(Sleeter, 2008). Ada beberapa prinsip dasar dari perspektif pendidikan multikultural yang memungkinkan peningkatan kemampuan akademik serta keunggulan beragam kelompok mahasiswa (Gollnick \& Chinn, 2002; Seidman, 2019) , diantaranya adalah (1) Perbedaan budaya memiliki kekuatan dan nilai ; (2) Sekolah dan perguruan tinggi harus menjadi model bagi masyarakat dalam mencerminkan penghormatan terhadap perbedaan budaya dan ekspresi hak asasi manusia ; (3) Keadilan sosial dan kesetaraan bagi semua orang harus menjadi sangat penting dalam desain dan kurikulum ; (4) Sikap dan nilai-nilai yang diperlukan untuk kelangsungan masyarakat demokratis dapat dipromosikan di sekolah dan pendidikan tinggi ; (5) Pendidik di institusi pendidikan tinggi bekerja sama dengan masyarakat lokal untuk menciptakan lingkungan yang mendukung penghormatan terhadap keragaman dan multikulturalisme.

Institusi pendidikan tinggi yang menganut prinsip-prinsip multikultural, maka mampu mencapai standar akademik yang tinggi, dan menjadi model bagi berbagai sekolah dan untuk masyarakat. Praktek-praktek akan diadopsi oleh lembaga pendidikan tinggi juga menjadi teladan bagi individu di masyarakat. Di negara yang memperjuangkan hak dan kesempatan yang sama bagi semua individu untuk meningkatkan kondisi hidup untuk semua, perhatian utama pendidik di lembaga pendidikan tinggi harus ditujukan untuk mempromosikan keberhasilan akademik, sosial, dan kepentingan semua siswa(Green, 1989).

Peningkatan keragaman ini mencerminkan keragaman bangsa dan dunia. Kenyataan menjadi lebih jelas di kampus-kampus di mana ada peningkatan keragaman minoritas. Institusi pendidikan tinggi adalah model untuk dunia yang saling bergantung. Para mahasiswa, dosen, dan staf di banyak kampus di dunia termasuk yang ada di Indonesia saat ini berasal dari berbagai negara. Mahasiswa, dosen, dan staf ini memiliki beragam

latar belakang budaya, ras, etnis, agama, dan sosial ekonomi. Apalagi saat ini telah menjadi kewajiban bagi perguruan tinggi untuk menerima mahasiswa dan mempekerjakan dosen dari berbagai latar belakang budaya, ras, etnis, agama, dan sosial ekonomi. Dengan kondisi ini universitas perlu menyediakan lingkungan 
yang mendukung yang menghormati keragaman dan menyediakan program yang inklusif bagi semua yang menjadi bagian darinya. Penyelenggara layanan kampus perlu memberikan layanan yang adil berbasis keragaman.

\section{KESIMPULAN}

Sampai saat ini, pendidikan multikultural difokuskan terutama pada pedagogi kesetaraan sebagai sarana untuk mengatasi masalah yang diciptakan oleh asimilasi atau perspektif "melting-pot" dari pendidikan multikultural. Hari ini, dengan interkoneksi yang meningkat pesat di antara semua negara-negara di dunia, terutama saat kita menghadapi isu-isu global terkait isu lingkungan, nuklir senjata, terorisme, hak asasi manusia, dan sumber daya nasional yang langka, ruang lingkup pendidikan multikultural harus diperluas untuk memasukkan perspektif global. Institusi pendidikan tinggi adalah model bagi masyarakat dan negara di mana mereka berada dan dapat berfungsi sebagai lokus untuk merangkul perspektif global tentang pendidikan multikultural. Empat prinsip dan dimensi interaktif dari perspektif global pendidikan multikultural yang memungkinkan perspektif global menjadi lebih berguna dalam mempromosikan nilai-nilai inti kemanusiaan daripada dibanding perspektif "melting-pot" adalah kompetensi multikultural, pedagogi kesetaraan, kurikulum ulang bentuk, dan pengajaran untuk keadilan sosial. Institusi pendidikan tinggi memiliki perspektif global dalam pendidikan multikultural tidak hanya akan menuai manfaat dari multikultural. Namun juga akan tetapi menjadi pilar keunggulan akademik, model demokrasi masyarakat yang pluralisistik, dan daya tarik untuk ekonomi internasional dan sumber daya manusia karena mereka hubungan manusia yang lebih baik dalam bangsa mereka sendiri dan dengan negara-negara lain di hari ini dunia yang semakin saling bergantung.

\section{UCAPAN TERIMA KASIH}

Jika perlu berterima kasih kepada pihak tertentu, misalnya sponsor penelitian, nyatakan dengan jelas dan singkat, hindari pernyataan terima kasih yang berbunga-bunga.

\section{DAFTAR PUSTAKA}

Ali, H. M. (2000). Guru Dalam Proses Belajar Mengajar. Pt Sinar Baru Algensindo. Https://Books.Google.Co.Id/Books?Id=Tpfdjweacaaj

Banks, J. A. (1993). Multicultural Education: Historical Development, Dimensions, And Practice. Review Of Research In Education, 19(1), 3-49. Https://Doi.Org/10.3102/0091732x019001003

Bennett, C. I. (1986). Comprehensive Multicultural Education: Theory And Practice. Allyn And Bacon Boston.

Budimansyah, D. (2012). Perancangan Pembelajaran Berbasis Karakter. Widya Aksara Press.

Christine E. Sleeter. (2007). Making Choices For Multicultural Education: Five Approaches To Race, Class And Gender. California State University, Monterey Bay Carl A. Grant.

Gollnick, D. M., \& Chinn, P. C. (2002). Multicultural Education In A Pluralistic Society.-6th Ed. New York: Merrill.

Green, M. F. (1989). Minorities On Campus: A Handbook For Enhancing Diversity. American Council On Education.

Lestari, A. S. (2015). Penerapan Pembelajaran Multikultural Berbasis Teknologi Dengan Pendekatan Konstruktivistik. Zawiyah Jurnal Pemikiran Islam, 1(1), 59-78.

Mcnergney, R. F., Herbert, J. M., \& Mcnergney, J. M. (2001). Foundations Of Education: The Challenge Of Professional Practice. Allyn And Bacon. Https://Books.Google.Co.Id/Books?Id=--Jvpgaacaaj 
5149 Pendidikan Multikultural: Sebuah Perspektif Global - Allyvia Camelia, Nikmah Suryandari DOI: https://doi.org/10.31004/edukatif.v3i6.1649

Nazir, M. (1985). Metode Penelitian. Ghalia Indonesia. Https://Books.Google.Co.Id/Books?Id=M_-Daqaacaaj

Nieto, S., \& Bode, P. (2018). Affirming Diversity: The Sociopolitical Context Of Multicultural Education. Pearson. Https://Books.Google.Co.Id/Books?Id=Yxhujweacaaj

Primawati, L. (2013). Dosen Fisipol Universitas Hkbp Nommensen Medan Jupiis Volume 5 Nomor 2, Desember 2013 82. 5, 82-92.

Ruslan, R. (2006). Metode Penelitian Relations: Public Relations Dan Komunikasi. Rajagrafindo Persada. Https://Books.Google.Co.Id/Books?Id=D0zgnqaacaaj

Seidman, A. (2019). Minority Student Retention: The Best Of The "Journal Of College Student Retention: Research, Theory \& Practice.” Taylor \& Francis. Https://Books.Google.Co.Id/Books?Id=Bf-Gdwaaqbaj

Shulman, J. H., \& Mesa-Bains, A. (2020). Diversity In The Classroom: A Casebook For Teachers And Teacher Educators. Diversity In The Classroom: A Casebook For Teachers And Teacher Educators, 4, 1-117. Https://Doi.Org/10.4324/9781315044781

Sleeter, C. E. (2008). Making Choices For Multicultural Education: Five Approaches To Race, Class And Gender, 6th Edition. Wiley Global Education. Https://Books.Google.Co.Id/Books?Id=Xracaaaaqbaj

Waston, A. A. (2018). Pendidikan Multikultural Dalam Perguruan Tinggi Islam Sebuah Implementasi Konseptual Pemikiran James A. Banks. Prosiding Konferensi Nasional Ke- 8 Asosiasi Program Pascasarjana Perguruan Tinggi Muhammadiyah (Appptma), 1-11. Isbn: 978-602-50710-9-6 